\title{
Didactic Module with Sphero Robotics: Approaches in Learning Programming
}

\author{
Astri Idayu Binti Athesan ${ }^{\mathrm{a}}$, Mohd Faizul Emizal Bin Mohd Ghazi ${ }^{\mathrm{b} *}$

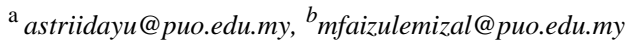 \\ Lecturer, Department of Information and Communication Technology, \\ Polytechnic Ungku Omar, Malaysia
}

\begin{abstract}
Education in $21^{\text {st }}$ century revolve among the context of knowledge-based economy which recognize knowledge as a source of competitiveness that emphasize in the increasing importance of science, research, technology, and innovation in knowledge creation; and the use of computers and the Internet to generate, share, and apply knowledge. This study discusses on the approaches and considerations used during the development of Sphero robot-based learning modules. The module was developed for the Problem Solving and Program Design course considering on two main factors restrictions of space and resource available to be mapped to related sub-topics involved that support Sphero activities. A didactic principal approach is also considered to be embed in the module where instruction related to learning that involve multidisciplinary are directly planned and present through the student's activities to achieve the learning objectives. In this paper, we discuss on four core components of Computational Thinking approach correlated to problem solving in learning programming. The development of module should stimulate student interest in learning programming concepts. The propose module does not focus on the use of Robotics as the main subject on its own, but as a tool during teaching and learning purposes to embed the simplicity of programming notion.
\end{abstract}

"Keywords: Didactic, Robotics, Computational Thinking, Programming, Knowledge-Base Economy"

\section{Introduction}

The 21st century portray the important role of education in determining the quality and ability of the new generation to adapt in the drastic phase changes of global civilization. Individuals who possess certain qualities such as the ability to use technology, efficient in problem solving, creative in generating collaboration and the ability to communicate are classified as more successful in the current industrial era.

According to Langworthy (2013), the economic drive changes from $20^{\text {th }}$ century of to only manufacture for mass market necessity towards the designing of knowledge-based product in $21^{\text {st }}$ century. Hence, it influences the learning challenge delivered by the educators from only the need to deliver the education content and information, and to only develop students' basic skills towards the approach of the need of creating product constructed on knowledge-based concepts and development of higher order skills (Langworthy, 2013). It means we are in the era of where knowledge is the key asset of the economy rather than in industrial societies.

Terms of "knowledge-based economy" is an expression invented to describe trends in progressive economies towards greater dependence on knowledge, information and high skill levels, and the increasing need for ready access to all of these by the business and public sectors (Organization for Economic CoOperation and Development, 2005). This context evolves on the complex relation of knowledge and technology to depends on the quality, amount and availability of information and knowledge rather than physical or natural resources. 
It orders to achieve this, one of the system renewals needed is through the Innovative Teaching Practice (ITP) approach. The approach involve combination of Student-Centered Pedagogies, Extending Learning, and ICT Integration as Table 1 is referred (Langworthy, 2013). This module applies only Knowledge construction and Collaborative for Student-Centered Pedagogies; Problem Solving concept in Extending Learning; and involved all practices implies in ICT integration option on the factors considered in developing Sphero Robotic module.

Table 1. Innovative Teaching Practices

\begin{tabular}{lll}
\hline Student-Centered Pedagogies & Extending Learning & ICT Integration \\
\hline Knowledge construction & Problem solving & By educators \\
\hline Personalized & $24 / 7$ learning opportunities & By students \\
Collaborative & Global and cultural understanding & Basic usage vs. Higher-level usage \\
& & (for knowledge building and \\
\hline Self-regulation & - & creativity) \\
\hline
\end{tabular}

\section{Didactic Learning}

Christina Osbeck, 2018 stated didactics as a ground of research that incorporates the collective knowledge of educators where academic knowledge and practice intersects to form an effective and efficient learning. The combination of multidisciplinary on different approach and theory are expected to grasp the diversity of learning forms among students. During the exploration by educator to arrange and apply the possible method of delivery, didactic may identify differences between explicit and implicit processes, and in that sense reveal a 'hidden curriculum' (Christina Osbeck, 2018). Asides, these diverse forms of approach may trigger the knowledge construction and creativity in problem solving both for educator and students.

The principles of didactic are normally arranged to anticipate and prearranged into practice of teachinglearning-evaluating activities, to ensure effectiveness of lesson competency in educational dimension (MariusCostel, 2010). The principle covered the scope for the lesson plan to be applicative, with specific dimension of what to achieve and able to accommodate the education process which require formative-informative correlations. Study by Marius-Costel, 2010 also have conclude didactic principles in which educator will gain benefits shown in Table 2.

Table 2. Didactic Principles Benefits

\begin{tabular}{ll}
\hline Principles & Description \\
\hline $\begin{array}{l}\text { The principle of the conscious and active } \\
\text { participation of students in the education process }\end{array}$ & $\begin{array}{l}\text { The lesson planned encouraged self-learning where student intent to } \\
\text { accomplish the learning objective }\end{array}$ \\
\hline $\begin{array}{l}\text { The principle of thorough acquisition of } \\
\text { knowledge, skills, and abilities }\end{array}$ & The lesson planned provides open-ended type of problem solving \\
\hline The principle of accessibility and individuality & The lesson planned uses student centered approach \\
\hline The principle of connecting theory with practice & $\begin{array}{l}\text { The lesson planned considered of the possible applied correlation of cognitive } \\
\text { input be delivered through application }\end{array}$ \\
\hline The principle of systematization and continuity & The lesson planned provides educational logic and connections in between \\
\hline The principle of intuition & The lesson planned support intuition interpretation \\
\hline The principle of reverse connection & The lesson planned support reasoning of feedback or retroaction \\
\hline
\end{tabular}


This study focusses on the Sphero Robotic as being the intermediate to deliver knowledge through the learning process. Its roles are as didactic tools where educators use it to assist in reaching the pedagogicaleducational goal (Klement, 2012). The modern didactic tools usually involve the mixture of Information Communication and Technology (ICT) surround with the multimedia element for a more user-friendly and interesting gears. This is also to ensure engagement of the generation $\mathrm{Z}$ as they grew up amongst the diverse usage of digital technology. Klement, 2012 stated, the aim of didactic tools is particularly to apply the principles of clearness by demanding technical composition of computer technology to transfer information from different sources.

Turning to this factor is why new demands has appeared in modern teaching paradigm for educators to be creative in forms of learning delivery. These demands have been identified also by Klement, 2012 through the research to be defined as TPCK model (Technological Pedagogical Content Knowledge) which also known as technological-didactic knowledge. An interactive robotic like Sphero is therefore one of the ways to innovate the teaching process and make use of all the possibilities of learning delivery. This thought is further supported with a statement from Brdička, 2009 saying "Only the combination of all necessary knowledge (technological-didactic-subject) makes the teacher a unique and irreplaceable master of their field who is able to help transfer learning towards higher forms in the current world conditions."

\section{Sphero Robotic Development Module}

\subsection{Basic of Computational Thinking (CT)}

Computational Thinking (CT) can be described in general as the ability to solve problems by human through the practice of interpretive thinking like a computer. In programming perspective, it involves the process of analyzing a complex problem, developing possible solutions to the problem, and formatting the solutions to be conducted later by a computer. Christodoulou et.al., emphasize the computational thinking as the teaching algorithmic thinking where algorithms and programming will be implemented to solve problem.

The context of Computational Thinking is point out by Barr et al., 2011 and Cooper et al., 2010 as an advantage to be mastered as it trains the way of thinking, processing, and problem-solving which then can be applied to the basic knowledge solution for other core subjects. A review by Mcclelland \& Instructional, 2018 then support the context further by the stating "An embedded learning activities using collaboratively defined literacies and the combination of computational thinking skills with the foundational skills tag along will help to establish the learning framework and foster creative thinking. It also able to prevent narrow interpretations and approaches to learning".

There are four core components of Computational Thinking. Figure 1 show the relation of CT with the components to guide the process of problem solving to be expected at its optimal result. To assist in the delivery of information on students' understanding with different levels of programming knowledge, Visual Programming Language (VPL) is applied. The concept of visual expression with real-time responses makes this method easier to deliver lessons, interesting and simple to use while being able to stimulate student interest. 


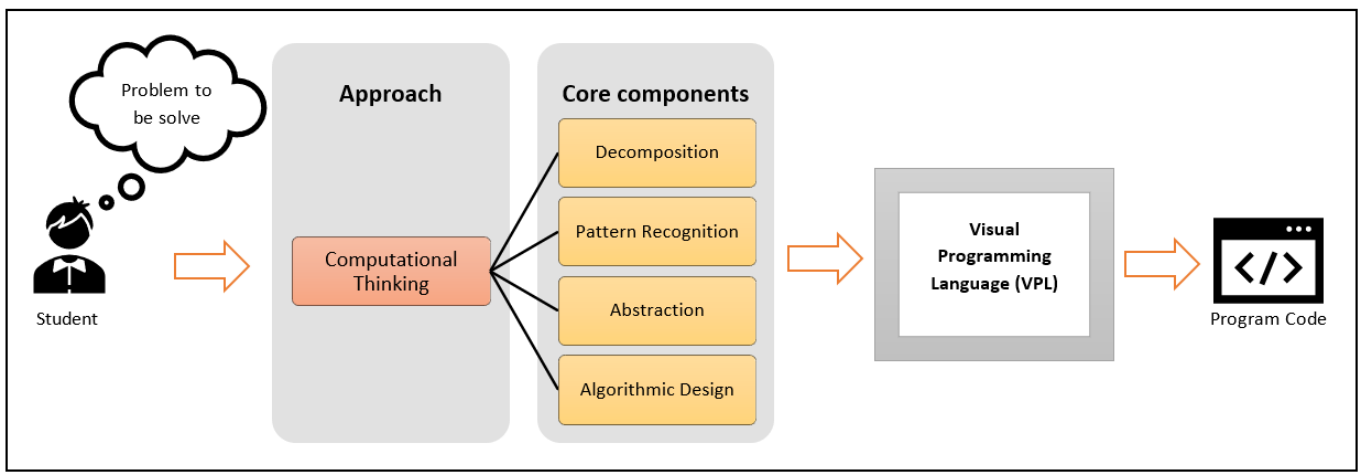

Fig. 1. Relation of Computational Thinking Approach with its Core Components

The description of each component is stated as in Table 3. An example of a problem to be solve are asserted to help further explain on how or when the core components apply about matters to be considered.

Table 3. The description of core components of Computational Thinking

\begin{tabular}{ll}
\hline Core Components & Description \\
\hline Decomposition & The problem is break into smaller chunks. \\
& $\begin{array}{l}\text { e.g; For sum of two input numbers, might involve thinking about the type of numeric } \\
\text { (integer, real number; for it to accept positive or negative value; or even the range of } \\
\text { number accepted). }\end{array}$ \\
\hline Pattern Recognition & To identify similarities or patterns in solving the problem. \\
& $\begin{array}{l}\text { e.g; For sum of two input numbers, might need to think about how many repeating } \\
\text { input questions and received data type it will occur. }\end{array}$ \\
\hline Abstraction & To remove any unnecessary details that cause ambiguity in problem solving. \\
& $\begin{array}{l}\text { e.g; For sum of two input numbers, that might mean the order in which you receive } \\
\text { the input number is not important. }\end{array}$ \\
\hline Algorithmic Design & $\begin{array}{l}\text { The accordingly broken-down problem will be solved individually, and later to be } \\
\text { combined logically. } \\
\text { e.g; For sum of two input numbers, this can mean determining the steps to either ask } \\
\text { for input first or to process calculation before displaying an output. For example, you } \\
\text { wouldn't be able to calculate the total if an input has not been received to be process. }\end{array}$ \\
\hline
\end{tabular}

\subsection{Computational thinking activities and factors affected}

Christodoulou et al., 2020 have list out groups of Computational ideas discussion comprising from the aspects of covered features, skills, evaluation, logical thinking, and attitudes and habits. Some involve the implicit terms of social skills while other focuses on the explicit categories covering features and skills which consist of the four core components. As stated in Table 3, the four main core components emphasized in Computational Thinking Fundamentals are Decomposition, Pattern Recognition, Abstraction and Algorithmic Design. 
This section will discuss on examples of activities need to be covered while developing the module. The considered Sphero activities should be able to support development of computational thinking mindset, with or without writing code. Listed in Table 4 are guidelines from the Sphero homepage on what to consider when lesson is planned.

Table 4. Considered Sphero Activities Guideline

\begin{tabular}{|c|c|c|}
\hline $\begin{array}{l}\text { Computational } \\
\text { Thinking Fundamentals }\end{array}$ & Description & Examples in Activities \\
\hline Decomposition & $\begin{array}{l}\text { Decomposition Does the activity encourage the } \\
\text { student to break a larger problem into smaller } \\
\text { problems to come up with a solution? }\end{array}$ & $\begin{array}{l}\text { Students solve complex problems } \\
\text { through smaller, more manageable tasks. }\end{array}$ \\
\hline Pattern Recognition & $\begin{array}{l}\text { Does the activity encourage the student to identify } \\
\text { common patterns? }\end{array}$ & $\begin{array}{l}\text { Students identify common patterns like } \\
\text { movement, speed, light, time, or } \\
\text { direction of the Sphero }\end{array}$ \\
\hline $\begin{array}{l}\text { Pattern Generalization } \\
\text { and Abstraction }\end{array}$ & $\begin{array}{l}\text { Does the activity encourage the student to make } \\
\text { connection about common patterns? }\end{array}$ & $\begin{array}{l}\text { Students connect concepts, such as speed } \\
\& \text { direction to how far Sphero traveled. }\end{array}$ \\
\hline Algorithm Design & $\begin{array}{l}\text { Does the activity encourage the student to create } \\
\text { logical steps that can be automated based on those } \\
\text { patterns and connections? }\end{array}$ & $\begin{array}{l}\text { Students create programs to control the } \\
\text { Sphero. These often require using } \\
\text { patterns like loops, which can be used to } \\
\text { automate repeated behavior. }\end{array}$ \\
\hline
\end{tabular}

As the question arises to response on the types of activities to be framed, Figure 2 shows the factors need to be considered that affect the type of lesson planned to deliver the topic. This figure is also use as a guideline in planning the module implement. It displays the factors affecting from the aspect of the size of the physical space and the resources available within which will have direct impact on the types and duration of lesson explores either individually or through collaboration.

In our study, as the resource are limited and lesson are done in laboratory consist of space limitation, activity plan inside the module is mostly in area (a) and (c). As an introduction and to have students familiarize with the education tools, physical education activities in (a) are considered as larger space are available. However, there are still limitation of space as the laboratory layout are design to be serves as a computer lab. To overcome these constraints, students are divided into further medium smaller groups.

To interact with the robot, an app call Sphero Edu should be installed. Sphero Edu is the Sphero app for programming Sphero robots and are accessible to be program using various platform. Working in collaboration, students can choose to explore the robots using Sphero Edu App through their smart device besides the lab path or to accommodate the available space inside the lab using the desktop.

The physical activities are expected to engaged students' interest as it applies hands-on mind on learning (Eguchi, 2014). This is because robotics technological frameworks are designed to engage students' curiosity and instigate motivation in the try and error context. As it supports learners' existing knowledge throughout the problem-solving experiments alternatively to their learning styles (Alimisis, 2012).

Next, considering the limited resources available like cost, time, number of robot available and the convenience of available equipment and internet facilities, activities are design to only covered section (c) in Basic Algorithm and Procedural Thinking which involve fewer resources. Thus, the activity plan must consider sharing the resource available. Content of the module are built on various multidisciplinary element to encourage creative thinking, attention and motivation considering the factors that no individual is a mastered of every expertise. 


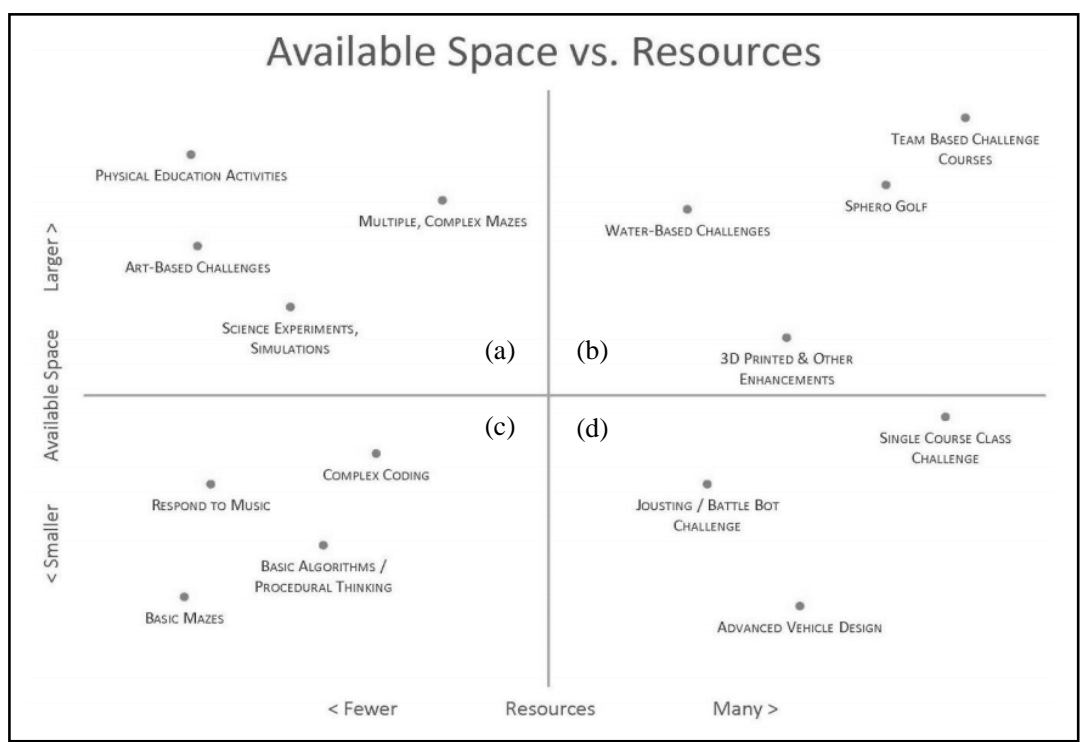

Fig. 2. Guideline on Relation of Lesson Planned Based on Available Resources and Space Used

All the activities for both areas are based on the mapping of subtopic related in the Problem Solving and Program Design course. Table 5 are referred. An additional reinforcement exercise is built in a form of Problem-Based Learning (PBL). The PBL method are based on student centered approach in which students learn about a subject by working in groups to solve an open-ended problem. A study by Jabarullah \& Iqbal Hussain, 2019 have identified through their analysis for the role of PBL as an arbitrator to encourage the learning process. Through PBL, students' shows growth in their performance which they benefit from experiential and student-centered learning approaches. Indirectly, students will also retain their knowledge when they obtain hands-on learning experience.

Table 5. Mapping the Related Subtopic with Suitable Module Activity

\begin{tabular}{|c|c|c|c|}
\hline No. & Subtopic & Mo & dule Activity \\
\hline \multirow[t]{2}{*}{1.} & Demonstrate Programming Life Cycle & (a) & Activity 1: Hello Sphero \\
\hline & & (b) & Sphero Challenge \#1 \\
\hline \multirow[t]{2}{*}{2.} & Identify problem solving concept & (a) & Activity 2: Geometry \\
\hline & & (b) & Sphero Challenge \#2 \\
\hline \multirow[t]{2}{*}{3.} & Describe the different types and patterns in algorithms to solve problem & (a) & Activity 3: Funny Me \\
\hline & & (b) & Sphero Challenge \#3 \\
\hline
\end{tabular}

\section{Conclusion}

The module develop are designed to be able to deliver the learning objective towards the related topics. To ensure the effectiveness of the module, factors affected corresponding to available space and resource must be considered during the module development. The development of this module is expected to enhance the students learning environment for Problem Solving and Program Design course. 


\section{Acknowledgements}

We would like to thank Information and Communication Technology Department, of Polytechnic Ungku Omar for allowing us to conduct this study.

\section{References}

Alimisis, D. (2012). Integrating robotics in science and technology teacher training curriculum. Proceedings of 3rd International Workshop Teaching Robotics, Teaching with Robotics Integrating Robotics in School Curriculum.

Barr, D., Harrison, J., \& Conery, L. (2011). Computational Thinking: A Digital Age Skill for Everyone. Learning and Leading with Technology.

Brdička, B. (2009). Jak učit ve všudy přítomném mraku informací? In P. Sojka, J. Rambousek (Eds.), SCO 2009, sborník 6. ročníku konference o elektronické podpoře výuky. Brno: Masarykova univerzita.

Christina Osbeck, A. I. (2018). Didactic classroom studies: A potential research direction. In Didactic classroom studies: A potential research direction. https://doi.org/10.21525/kriterium.14

Christodoulou, M., Kłapa, Ł., Kolarz, W., \& Szczygieł, E. (2020). Algorithmic and Programming. Didactics Training materials for Teachers (Issue May 2018).

Cooper, S., Pérez, L. C., \& Rainey, D. (2010). Education: K-12 computational learning. In Communications of the ACM. https://doi.org/10.1145/1839676.1839686

Eguchi, A. (2014). Robotics as a Learning Tool for Educational Transformation. International Workshop Teaching Robotics, Teaching with Robotics \& International Conference Robotics in Education.

Jabarullah, N. H., \& Iqbal Hussain, H. (2019). The effectiveness of problem-based learning in technical and vocational education in Malaysia. Education and Training. https://doi.org/10.1108/ET-06-2018-0129

Klement, M. (2012). Modern Didactic Tools and the Possibilities of Their Implementation Into the Educational Process. Problems of Education in the 21st Century, 39(2001), 82-93.

Langworthy, M. (2013). 21 st CENTURY LEARNING DESIGN Learning that matters.

Marius-Costel, E. (2010). The Didactic Principles and Their Applications in the Didactic Activity. Online Submission, 7(9), $24-34$.

Mcclelland, K., \& Instructional, L. G. (2018). A review of the importance of computational thinking in K-12. The Tenth International Conference on Mobile, Hybrid, and On-Line Learning, c, 32-34. https://doi.org/10.1007/s11528-016-CITATIONS

Organization for Economic Co-Operation and Development. (2005). The Measurement of Scientific and Technological Activities: Guidelines for Collecting and Interpreting Innovation Data. In Oslo Manual. 